\title{
Do selective serotonin receptor inhibitor antidepressants reduce tamoxifen's effectiveness and increase the risk of death from breast cancer?
}

\author{
Kathleen I Pritchard*
}

Tamoxifen has been shown over the past 30 years to be extremely effective in the treatment of estrogen receptor (ER)-positive breast cancer. The drug is widely used in the adjuvant setting where it reduces the risk of breast cancer recurrence by almost $40 \%$ and the risk of death from breast cancer by one-third [1]. It is now known that tamoxifen acts as a pro-drug. Its major active metabolites are N-desmethyl tamoxifen, which has a low affinity for ER, 4-hydroxy tamoxifen (4HT) and 4-hydroxy-Ndesmethyl-tamoxifen (endoxifen). Endoxifen and 4HT have by far the highest affinity for ER and since endoxifen is produced in six to ten times the concentration of $4 \mathrm{HT}$ it is felt to be the most important metabolite.

CYP2D6 is an enzyme of the cytochrome P450 family, subfamily D, found on chromosome 22. It catalyzes tamoxifen's metabolism and is encoded by a large polymorphic gene with more than 80 allelic mutations identified. Inherited variations alter the function of CYP2D6 and the geographic and ethnic distributions of these polymorphisms are varied. Drugs given concurrently can also alter the function of CYP2D6 by competing for its activity.

The metabolic pathway of tamoxifen is shown in Figure 1. As can be seen, CYP2D6 catalyzes both tamoxifen's primary and secondary metabolism.

CYP2D6 phenotypic expression can be divided into three groups: those with little or no enzyme activity (poor or intermediate metabolizers); those with normal enzyme activity (extensive metabolizers); and those with greatly increased enzyme activity (ultrarapid metabolizers). Several studies have shown that relapse free time and disease free survival as well as overall survival in women treated in the adjuvant setting with tamoxifen vary according to the presence of variants that produce ultrarapid, intermediate or low metabolism [2]. Results

*Correspondence: Kathy.Pritchard@sunnybrook.ca

Sunnybrook Odette Cancer Centre, 2075 Bayview Avenue, Toronto, Ontario M4N 3M5 Canada are, however, contradictory, with at least ten studies showing positive association between these genotypes and outcome and another eight showing no association [3]. Thus, evidence is contradictory as to how important CYP2D6 levels are to outcome with adjuvant tamoxifen therapy. The ideal study to confirm or refute the value of this association would be a randomized trial of tamoxifen versus no treatment as adjuvant therapy with these enzymes and endoxifen levels measured and correlated with the outcomes of recurrence and survival.

In addition, a number of common drugs are known to be inhibitors of CYP2D6. Strong inhibitors include drugs such as chlorpromazine, fluoxetine, miconazole, paroxetine, quinidine and quinine whereas moderate inhibitors include cimetidine, diphenhydramine, haloperidol, ketoconazole, methadone, nicardipine and sertraline. Some selective serotonin receptor inhibitor (SSRI) antidepressants, such as venlafaxine (Effexor), are quite weak inhibitors of CYP2D6 activity.

Kelly and colleagues [4] have recently shown in an observational population-based study from Ontario, Canada that women prescribed antidepressants, in particular paroxitene, concomitantly with tamoxifen adjuvant treatment had increasing breast cancer-related and/or all cause mortality whereas patients treated with the concomitant use of other antidepressants that are not such strong inhibitors, such as sertraline, fluvoxamine, fluoxetine and particularly venlafaxine, did not have this effect. Again, the interpretation of this study is limited by its observational design and the lack of measurement of endoxifen levels, which could help to draw the sort of direct conclusion one might like.

In summary, tamoxifen pharmacogenetic studies in the past 20 years have detected a new active metabolite, endoxifen, which is likely most important in predicting outcome in relation to adjuvant therapy with tamoxifen. Several recent studies show a clear negative interaction between paroxitene and tamoxifen metabolism to endoxifen while other SSRIs such as venlafaxine do not appear to produce this effect. While it is clear that CYP2D6 plays an important role in tamoxifen 


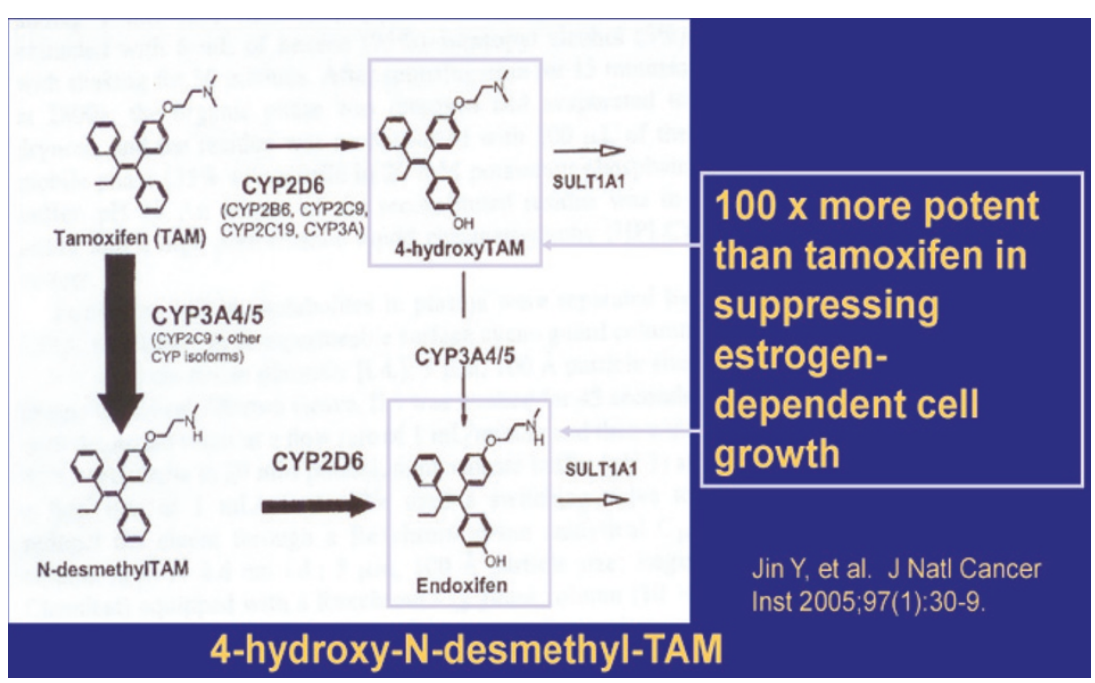

Figure 1. Metabolic pathway of tamoxifen.

metabolism and that drugs such as SSRIs can alter the phenotype, no consensus has been reached regarding the incorporation of CYP2D6 genotype testing in routine clinical practice, although an excellent recent review of this subject suggests that such testing may be useful [5]. Decisions to conduct genotype testing should still be individualized based on clinical indication and patient preference. Clinical trials to clarify this situation should be well designed, adequately powered prospective studies with strict inclusion criteria, genotype testing and endoxifen levels.

\section{Abbreviations}

4HT, 4-hydroxy tamoxifen; ER, estrogen receptor; SSRI, selective serotonin receptor inhibitor.

\section{Competing interests}

The author declares that she has no competing interests.

\section{Acknowledgements}

This article has been published as part of Breast Cancer Research Volume 12 Supplement 4, 2010: Controversies in Breast Cancer 2010. The full contents of the supplement are available online at http://breast-cancer-research.com/ supplements/12/S4

Published: 20 December 2010

\section{References}

1. Early Breast Cancer Trialists' Collaborative Group (EBCTCG): Effects of chemotherapy and hormonal therapy for early breast cancer on recurrence and 15-year survival: an overview of the randomised trials. Lancet 2005, 365:1687-1717.

2. Goetz MP, Rae JM, Suman VJ, Safgren SL, Ames MM, Visscher DW, Reynolds C, Couch FJ, Lingle WL, Flockhart DA, Desta Z, Perez EA, Ingle JN:

Pharmacogenetics of tamoxifen biotransformation is associated with clinical outcomes of efficacy and hot flashes. J Clin Oncol 2005, 23:9312-9318.

3. Dezentje VO, Van Schaik R, Vletter-Bogaartz JM, Wessels JS, Hille ET, Seynaeve C, Van De Velde CJ, Nortier JW, Gelderblom H, Guchelaar H:

Pharmacogenetics of tamoxifen in relation to disease-free survival in a Dutch cohort of the tamoxifen exemestane adjuvant multinational (TEAM) trial [abstract]. J Clin Oncol 2010, 28 (suppl):abstact 510

4. Kelly CM, Juurlink DN, Gomes T, Duong-Hua M, Pritchard KI, Austin PC, Paszat LF: Selective serotonin reuptake inhibitors and breast cancer mortality in women receiving tamoxifen: a population based cohort study. BMJ 2010, 340:c693.

5. Sideras K, Ingle JN, Ames MM, Loprinzi CL, Mrazek DP, Black JL, Weinshilboum RM, Hawse JR, Spelsberg TC, Goetz MPa: Coprescription of tamoxifen and medications that inhibit CYP2D6. J Clin Oncol 2010, 28:2768-2776.

doi:10.1186/bcr2747

Cite this article as: Pritchard KI: Do selective serotonin receptor inhibitor antidepressants reduce tamoxifen's effectiveness and increase the risk of death from breast cancer?. Breast Cancer Research 2010, 12(Suppl 4):S18. 